\title{
LAS NUEVAS FRONTERAS DE LOS DERECHOS FUNDAMENTALES EN EL ORDENAMIENTO ITALIANO: CRÓNICA DE UN LENTO AVANCE
}

\author{
CARLOS ORTEGA SANTIAGO \\ Profesor de Derecho Constitucional \\ Universidad de Valladolid
}

\author{
SUMARIO \\ I. Introducción. \\ II. Ciudadanía y emigración. \\ III. Familia y matrimonio. \\ IV. Fecundación asistida y bioética. \\ V. Tutela de derechos: Autoridades inde- \\ pendientes y TEDH.
}

\section{INTRODUCCIÓN}

En los últimos años el debate sobre los derechos fundamentales y las dimensiones subjetivas en que despliegan su eficacia se viene centrando en nuevos espacios abiertos al Derecho Constitucional por la fuerza de los hechos. Así ha ocurrido con las cuestiones vinculadas a la ciudadanía y a los derechos de los extranjeros, con las nuevas formas de agrupación social nuclear más allá de la familia tradicional fundada en el matrimonio, o con todos los problemas que han suscitado los nuevos avances científicos para los que se precisan nuevas respuestas desde la ética y el derecho.

Al mismo tiempo, resulta relevante que estos nuevos retos del Derecho Constitucional de los derechos fundamentales se presenten con similares ropajes en todos los ordenamientos que pueden englobarse en la tradición jurídica occidental. Eso conlleva que las soluciones jurídicas a todas esas cuestiones se comuniquen con facilidad de unos países a otros y que, en ocasiones, los propios Estados se comprometan a través de tratados u otro tipo de disposiciones supranacionales a un tratamiento homogéneo de estos 
fenómenos. De cualquier forma, ocurre también que la subsistencia del Estado soberano trae consigo la pervivencia de regulaciones jurídicas nacionales peculiares, en algunas ocasiones muy alejadas de las reglas de tendencia que enmarcan las tomas de posición jurídica adoptadas en otros países.

Así sucede, en concreto, con el ordenamiento italiano en cuanto a determinadas situaciones de actualidad (el reconocimiento jurídico de la convivencia entre dos personas y el surgimiento de derechos y obligaciones recíprocos en su seno; la fecundación asistida y el tratamiento de embriones...). A este respecto, llama la atención que las peculiaridades del ordenamiento de ese país se han derivado, en buena medida, de la influencia social y política que ha desplegado la Iglesia Católica acerca de estos temas y que ha contado con una especial receptividad en la anterior mayoría de gobierno. Todo ello a partir de un texto constitucional lo suficientemente dúctil como para habilitar al legislador italiano a disciplinar estos asuntos con mayor amplitud de miras, a pesar de la impronta que dejó el sector católico de la Constituyente en algunos preceptos de la Constitución de 1948.

Otro aspecto relevante que debe señalarse de partida es que el sistema político italiano no ha sido capaz de generar un mínimo consenso entre mayoría y oposición para alumbrar una regulación de estas materias lo suficientemente aceptada, ni de extender por tanto ese consenso a los diferentes actores sociales. Esta realidad constituye un evidente peligro para la estabilidad de regulaciones jurídicas cuya verdad axiológica es muy difícil de determinar y que no pueden quedar, por ello, al albur de las distintas mayorías parlamentarias en presencia. En estas nuevas fronteras de los derechos fundamentales se hace más necesario que en otros supuestos legitimar la ley a través del pluralismo y el procedimiento (non veritas nec auctoritas sed pluritas facit legem), intentando llegar a formulaciones normativas que no generen un rechazo radical en una parte del espectro social y político, puesto que ese rechazo no es sino el anuncio de un concurso abierto por ver quien escribirá la ley mejor.

Por último, en esta crónica se hará referencia, de manera sucinta, a otros aspectos relacionados con los derechos fundamentales, no tan polémicos como los relativos a la bioética o al matrimonio o la familia, pero sí de evidente actualidad por conllevar tratamientos novedosos a problemas clásicos de los derechos y de su tutela. Así, se hará mención a la relevancia de las autoridades independientes en la salvaguarda de los derechos fundamentales (en el ámbito de la privacy y de la libertad de información); y a la eficacia no meramente declarativa de las sentencias del TEDH en el ámbito interno italiano.

\section{CIUDADANÍA Y EMIGRACIÓN}

Como en la mayor parte de los países europeos, también en Italia la emigración constituye una de las cuestiones que requieren una mayor intervención de los poderes públicos para salvaguardar al máximo la pluralidad de intereses y de derechos en juego. Sólo en el año 2006 el número de inmi- 
grantes con permiso de residencia en ese país era de 2.670.000, aumentando en más de un 11\% la cifra del año anterior. A nadie se le escapa la variedad de propuestas políticas que pretenden afirmarse como el mejor tratamiento para esta cuestión, ni la incidencia que tienen las peculiaridades de cada Estado para justificar un tratamiento soberano de este asunto, por más que en el ámbito de la Unión Europea se intente dar una respuesta común y coordinada al mismo.

Esto explica la intensidad con la que la nueva mayoría de gobierno italiana pretende abordar la integración social y política de los extranjeros, de la mano del Ministro G. Amato. En este sentido, el ejecutivo ha propuesto al Parlamento variaciones en el tratamiento de la emigración que se concretan en medidas sancionadoras (previsión de un nuevo delito de "transporte de extracomunitarios clandestinos"), en una nueva disciplina de los permisos de residencia que prevé reducir de seis a cinco años el período de estancia en Italia para obtener la autorización de residencia permanente (disciplina más acorde con las previsiones del ordenamiento comunitario al respecto - $\mathrm{Di}$ rectiva 2003/86/CE, relativa al Estatuto de los nacionales de terceros países residentes de larga duración-), o en un tratamiento renovado de la inmigración por motivos de trabajo que pretende lograr la selección de los trabajadores emigrantes ya en sus países de origen.

No obstante, pueden revestir mayor importancia respecto de la igualación jurídica de los extranjeros a los nacionales italianos las propuestas avanzadas en relación con la adquisición de la ciudadanía italiana, puesto que las políticas de la emigración se caracterizan por una nota de inestabilidad al estar sujetas, en el espacio europeo, a continuos movimientos pendulares derivados de la realidad fáctica de los flujos migratorios y de las variadas instancias decisorias (europea, estatal, regional). En este sentido, el gobierno Prodi ha presentado ante el Parlamento un proyecto de ley de modificación de las normas sobre la ciudadanía que supone un giro importante en la disciplina legal vigente actualmente en Italia y que se remonta a 1992 (ley núm. 91).

Esta ley se basa fundamentalmente en los criterios del ius sanguinis y sólo excepcionalmente en los del ius soli, mientras que la propuesta Amato refuerza los supuestos de adquisición de la nacionalidad por nacimiento en territorio italiano (para el hijo de padres extranjeros con residencia permanente en ese país, cuando al menos uno de ellos lleve residiendo de manera legal en Italia al menos cinco años o haya nacido en Italia), o por residencia en el mismo (cuando el bijo que pretende adquirir la nacionalidad, no nacido en Italia, haya cumplido un ciclo escolar, un curso de formación o un año de trabajo regular en el país, siempre que al menos uno de los padres sea residente permanente o baya nacido en Italia).

Como es sabido, la adquisición derivada de la nacionalidad plantea dos problemas relevantes desde la perspectiva de la subsistencia de una comunidad política que comparte unos valores comunes (en los estados democráticos contemporáneos se suele apelar a la Constitución como corporeización de ese proyecto común de la comunidad de ciudadanos): por una parte, el modo de 
verificar que el extranjero acepta y asume como propios el sistema de valores civiles y políticos que sustentan a la comunidad; por otra parte, la inconveniencia que supone a este respecto las situaciones de doble nacionalidad.

Todo ello porque los nacionales son los que dotan a la comunidad de su modo peculiar de ser, fundamentalmente a través del ejercicio de los derechos políticos (según la concepción de Mortati). Y no puede olvidarse que, en los ordenamientos jurídicos europeos, donde la tendencia normativa es a situar a los extranjeros (incluso los que no residen legalmente en el país) en igualdad de derechos - por su vinculación con la dignidad humana- con los nacionales, la ciudadanía dota de ese plus de status a sus titulares que se concreta, precisamente, en la titularidad de los derechos políticos.

Por esta razón, es esencial a una disciplina normativa que pretenda ampliar los supuestos de adquisición de la nacionalidad, la previsión de mecanismos adecuados para confrontar la integración real, social y política, del extranjero con derecho a acceder a la ciudadanía. No basta para ello, evidentemente, con el conocimiento adecuado de la lengua o lenguas oficiales del Estado, ni con el cumplimiento de la fórmula ritual del juramento o promesa de la Constitución; por esta razón, el proyecto de ley italiano al que nos referimos, al tiempo que facilita la adquisición de la nacionalidad, habilita al reglamento de desarrollo para establecer los criterios de verificación de dicha integración. Alguna doctrina llega a plantear, incluso, que un criterio especialmente apto para atestiguar la voluntad de integración política en la nueva comunidad sería, precisamente, la renuncia a la ciudadanía de origen ${ }^{1}$.

En todo caso, las reflexiones que se acaban de hacer acerca de la disciplina legal en tramitación actualmente en el Parlamento italiano ponen de manifiesto que el proceso de incorporación del otro (del extranjero) a la comunidad política nacional no puede considerarse plena, y no lo es, si no cuenta con una equiparación jurídica en cuanto a la titularidad de los derechos, incluidos los políticos. A este respecto, los ordenamientos nacionales se muestran claramente refractarios a esta posibilidad, por más que se intenten concretar vías alternativas de participación política de los extranjeros (en España, incluso a través de la iniciativa legislativa popular, como prevé la reciente Ley aprobada por el Parlamento de Cataluña sobre esta materia, con algunos preceptos de difícil anclaje constitucional).

Por ello, para el desarrollo futuro de los derechos fundamentales adquirirán especial relevancia las previsiones legales sobre la adquisición de la nacionalidad, como único modo de lograr que el otro deje de ser tal y se convierta plenamente en uno de los nuestros. Por lo demás, ese es el camino que se apunta en el Convenio Europeo sobre la nacionalidad firmado en Estrasburgo el 6 de noviembre de 1997, por impulso del Consejo de Europa, que no han ratificado aún ni España ni Italia.

1 Así V. Lippolis, "Il disegno di legge Amato e i requisiti per l'acquisto della cittadinanza: perchè non ripensare il sistema della doppia cittadinanza", en Forum di Quaderni Costituzionali. 


\section{FAMILIA Y MATRIMONIO}

Otra propuesta legislativa planteada por el gobierno Prodi, la que pretende regular los derechos y deberes de las personas con convivencia estable, ha generado una fuerte polémica, contando con la oposición frontal de la Iglesia Católica y ocasionando un encendido debate doctrinal en el seno del Derecho Constitucional; debate que pone de manifiesto, sin duda, que el método científico también tiene ideología, y más si cabe el del Derecho².

Lo significativo de esa regulación es que es especialmente cauta en cuanto a la definición de los derechos y de los deberes de las personas con convivencia estable, en la línea de las regulaciones más moderadas que pueden encontrarse sobre la materia en el derecho comparado, y ciertamente muy alejada de aquellos ordenamientos donde se ha dado un salto cualitativo en el reconocimiento de nuevas formas de convivencia y de matrimonio (como pueda ser, por ejemplo, el Código Civil español tras las modificaciones introducidas con la Ley 13/2005, de 1 de julio).

La propuesta legislativa parte de la no fungibilidad (heterogeneidad) entre uniones de hecho y matrimonio. En el seno de las primeras, cuya realidad fundante es la existencia de una relación afectiva entre las partes (de la que el registro no es sino prueba declarativa), el proyecto de ley reconoce derechos y deberes dotados de plena lógica, en algunos casos ya previstos en disciplinas sectoriales o reconocidos por la jurisprudencia, derechos y deberes que un sistema jurídico atento a la realidad social que pretende ordenar no puede dejar de tomar en consideración (derecho a la protección social, derecho de asistencia sanitaria, sucesión en los contratos, derecho a la legitima en la sucesión abintestato, obligación de alimentos...). En cualquier caso, el proyecto no atribuye a esas uniones de hecho derechos y deberes que sólo pueden nacer del matrimonio (de manera relevante, el derecho de adopción), en los términos afirmados por la propia Corte Constitucional a partir de lo dispuesto en el art. 29 de la Constitución.

Es este precepto constitucional, en el que se dispone que "La República reconoce los derechos de la familia como sociedad natural fundada sobre el matrimonio. El matrimonio se ordena a partir de la igualdad moral y juridica de los cónyuges, con los límites establecidos en la ley como garantía de la unidad familiar, el que ha servido de apoyo a aquéllos que consideran que no se ha de dotar de reconocimiento público (legal) a las uniones de hecho, puesto que eso supondría institucionalizar un nuevo modelo de familia al margen de lo previsto en la Constitución. Determinados beneficios (derechos) que corresponden a los cónyuges por el carácter propio del negocio jurídico

2 Como documentos significativos se pueden citar el "Discurso de Benedicto XVI en el Convenio del Partido Popular Europeo", recogido en "La verità sulla famiglia. Matrimonio e unione di fatto nelle parole di Benedetto XVI", Quaderni de L'Osservatore Romano, Ciudad del Vaticano, 2007; o la "Nota a riguardo della famiglia fondata sul matrimonio e di iniziative legislative in materia di unioni di fatto", emanada por el Consejo Episcopal Permanente el 28 de marzo de 2007. 
matrimonial, podrían considerarse potestativos para las uniones de hecho; pero si así se reconociera por el legislador se estaría diluyendo y debilitando el matrimonio, especialmente protegido por el texto constitucional ${ }^{3}$.

Sin embargo, el alcance que ha dado la Corte al precepto del art. 29, en una interpretación sistemática con el resto de la Constitución, conlleva, sí, que determinados derechos y deberes sólo nazcan del matrimonio, pero supone también que la familia matrimonial no es la única familia que encuentra reconocimiento en el texto constitucional. Más en concreto, la Corte Constitucional ha tenido ocasión de afirmar que la familia de hecho (convivencia more uxorio) no es constitucionalmente irrelevante, siendo sus integrantes titulares también de derechos propios de los cónyuges que forman el matrimonio (Sentencia núm. 404 de 1988); protección de la familia de hecho que encuentra su anclaje constitucional en las previsiones del art. 2 ("La República reconoce y garantiza los derechos inviolables del hombre, ya sea individualmente ya sea en las formaciones sociales donde se desarrolla su personalidad...").

La definición de la familia fundada en el matrimonio como "sociedad natural" lleva también a esa doctrina a considerar que el Constituyente ha incorporado al texto constitucional un solo tipo de matrimonio, el que se encuentra enraizado en el tejido social y dispone de un reconocimiento consuetudinario, el matrimonio fundado en la monogamia, la exogamia y la heterosexualidad. Por ello, para reconocer nuevos tipos de convivencia o nuevas formas de matrimonio con los mismos o similares derechos que el matrimonio tradicional, sería necesario reformar previamente el texto constitucional. En otras palabras, el matrimonio constitucionalmente reconocido no puede ser un simple contenedor que el legislador pueda rellenar a placer.

Esta última afirmación supone admitir que hay un concepto constitucional de matrimonio, no explicitado en el texto de la Constitución pero sí deducible del término "sociedad natural" y de la voluntad y el espíritu del Constituyente. Afirmación que se puede compartir, como punto de partida, pero que no tiene porqué llevar a excluir el reconocimiento de otros tipos de convivencia o de matrimonio. Y ello porque el concepto de matrimonio enraizado en el tejido social puede evolucionar con la propia evolución de la sociedad; la naturalidad de esa sociedad primaria que es la familia, y del matrimonio que la sustenta, no puede indagarse como si se tratara de un ser ontológicamente inmutable. El legislador podría concretar normativamente visiones actualizadas de esa sociedad natural, y la Corte Constitucional podría tomar en consideración el sustrato social, en cada momento histórico, para determinar qué formas de unión afectiva se pueden considerar como sociedades naturales ${ }^{4}$.

3 Véase en este sentido, por ejemplo, A. Ruggeri, «Idee sulla famiglia e teoria (e strategia) della Costituzione", en Forum di Quaderni Costituzionali.

4 En la doctrina italiana, C. Esposito apunta desde un primer momento que el art. 29 de la Constitución no contiene una definición platónica de la familia que haya de concretarse a partir del derecho natural ("Famiglia e fligli nella Costituzione italiana", en La Costituzione italiana. Saggi, Cedam, Padua, 1954). 
Desde este punto de vista, y teniendo en cuenta las peculiaridades del ordenamiento italiano que derivan ya del propio texto constitucional, no parece incompatible con la Constitución la regulación de las uniones de hecho, siempre que su régimen jurídico no se asimile al del matrimonio, y cabría también que esas uniones se constituyeran por personas del mismo sexo vinculadas por una relación afectiva. Más difícil resulta, a partir de una exégesis del art. 29, admitir que pueda prescindirse del principio de la heterosexualidad entre los cónyuges para que pueda existir matrimonio; sin que sea necesario, para ello, considerar que la eliminación de este elemento arrastraría la desaparición de los otros dos (principalmente la monogamia, en razón incluso de la integración multicultural, puesto que aquí están en juego otros principios constitucionales como la igualdad) ${ }^{5}$.

Pero la visión tradicional de la familia que empapa el ordenamiento italiano tiene otras manifestaciones que han sido reparadas, esta vez, por vía jurisprudencial. Así ocurre con el entendimiento patriarcal de la familia que se plasma a través del apellido que se transmite a los hijos: en este país cada persona se identifica con el nombre y un solo apellido que, según las previsiones del Código Civil, ha de ser en todo caso el del padre, en ningún caso el de la madre, ni siquiera si media consenso entre los progenitores.

En una decisión relevante, la Sentencia núm. 61 de 2006, la Corte Constitucional modifica su anterior jurisprudencia, en la que había afirmado la constitucionalidad de la transmisión únicamente del apellido paterno por tratarse de "una regla enraizada en los usos sociales" que serviría como criterio de tutela de la unidad de la familia fundada en el matrimonio (Ordinanza núm. 586 de 1988), pasando a considerarla como una regla discriminatoria basada en una concepción patriarcal de la familia que lesiona la igualdad de la mujer en el matrimonio, sin que esa desigualad de trato pueda justificarse en la garantía de la unidad familiar (según lo dispuesto en el art. 29 de la Constitución italiana).

No obstante, la Corte constitucional realiza este enjuiciamiento en los fundamentos de la Sentencia, pero no los traslada al fallo, que contiene una decisión de inadmisibilidad de la cuestión de inconstitucionalidad que da lugar a la Sentencia. La razón es que, para dotar de efectividad a su declaración de inconstitucionalidad, la Corte debería construir una sentencia manipuladora estableciendo la regulación legal apta para acabar con esa discriminación; pero, ante la variedad y heterogeneidad de opciones normativas aptas para alcanzar esa finalidad, una decisión de ese tipo excedería de las funciones propias del legislador negativo que es la Corte constitucional. La reparación de la inconstitucionalidad habrá de realizarse, en consecuencia, por el legislador.

La trascendencia del apellido como parte integrante del nombre al que se tiene derecho como emanación del derecho a la identidad personal (derechos

5 Cfr. en este sentido C. Pinelli, "La Nota del Consiglio Episcopale Permanente e le norme costituzionali in tema di famiglia e formazioni sociali", en Associazione Italiana dei Costituzionalisti. 
que forman parte de los derechos inviolables de la persona a los que se refiere el art. 2 de la Constitución italiana, según constante jurisprudencia de la Corte), se ha puesto de manifiesto en otro asunto resuelto por un tribunal ordinario italiano con base en la jurisprudencia del Tribunal de Justicia de las Comunidades Europeas (contenida en la Sentencia de 2 de octubre de 2003, asunto C-148/2002). Resulta relevante que dicho órgano judicial haya podido llegar a una solución más acorde con la Constitución y con la igualdad entre los cónyuges referida, a través de la inaplicación de la ley italiana (el Código Civil) por su incompatibilidad con el derecho comunitario.

En concreto, el tribunal italiano ordenó la inscripción en el registro de un niño con los apellidos de su padre y de su madre, teniendo en cuenta la doble nacionalidad del menor (padre italiano y madre portuguesa) y que en el ordenamiento portugués los hijos reciben los apellidos de ambos progenitores. Solución jurídica basada en los arts. 12 y 17 del Tratado Constitutivo de la Comunidad Europea (prohibición de discriminación por razón de nacionalidad y ciudadanía de la Unión) que pone de manifiesto, al mismo tiempo, una situación de discriminación inversa que ha sido apuntada por la doctrina, puesto que a los nacionales del Estado miembro en cuestión no se les podría dejar de aplicar su legislación interna ${ }^{6}$.

La Corte Constitucional italiana ha evolucionado también su jurisprudencia, reinterpretando la Constitución, respecto de la desigualdad entre los hijos naturales y los hijos legítimos. El propio texto constitucional parece avalar, en principio, una posible diferencia de trato, al disponer que "Es deber y derecho de los padres mantener, instruir y educar a los hijos, también a los nacidos fuera del matrimonio... La ley asegura a los hijos nacidos fuera del matrimonio todo tipo de tutela juridica y social, siempre que sea compatible con los derechos de los miembros de la familia legítiman; diferencia de trato que ha tenido su plasmación después en vía legislativa.

En la sentencia núm. 50 de 2006 la Corte Constitucional se enfrenta con una regulación procesal que establecía un procedimiento indagatorio previo - diferenciado - cuando la acción de reconocimiento de la paternidad o maternidad era ejercida por un bijo natural (procedimiento secreto y sumario), procedimiento que tendría por objeto evitar acciones vejatorias o de chantaje. La Corte basa su declaración de inconstitucionalidad en que el precepto cuestionado del Código Civil no puede satisfacer ya las finalidades que le dieron origen, y no puede hacerlo porque está en juego el derecho del hijo a conocer la veracidad de su filiación (con independencia de que surja dentro o fuera del matrimonio) como garantía del pleno desarrollo de la personalidad.

6 Véase en general, sobre este tipo de discriminación inversa, entre nuestra doctrina, el fundamental trabajo de D. Sarmiento, Poder Judicial e Integración Europea. La construcción de un modelo jurisdiccional para la Unión, Thomson-Civitas, Madrid, 2004. 


\section{FECUNDACIÓN ASISTIDA Y BIOÉTICA}

En el ámbito de la fecundación asistida, con todas las connotaciones de índole ético-jurídica que comporta, el ordenamiento italiano se sitúa también un paso por detrás de los ordenamientos constitucionales de su entorno, merced a una disciplina legal que ha suscitado críticas doctrinales desde diferentes puntos de vista ${ }^{7}$. Se trata de una regulación legal de las que la Corte constitucional denomina "de contenido constitucional vinculado", que no pueden ser derogadas sin otra regulación que las sustituya puesto que, en ese supuesto, quedarían sin garantía principios o derechos constitucionales esenciales que encuentran desarrollo o tutela en la propia ley; lo cual justifica que sea una disposición legal cuya abrogación in totto no puede someterse a referéndum popular (sentencia 45 de 2005).

Que la Ley 40 de 2004 "en materia de procreación asistida médicamente" ha resultado polémica y no ha sido fruto de un consenso mínimo en el seno del pluralismo social y político se ha puesto de manifiesto, por ejemplo, en que ha sido objeto de varias propuestas de referéndum derogador sobre cuya admisión ha debido pronunciarse la Corte Constitucional (sentencias núms. 45 a 49 de 2005), con pronunciamientos diferentes en función de los contenidos afectados de la ley. En todo caso, los referendos admitidos y que se han llegado a celebrar no han satisfecho los requisitos legales para que la derogación legal prosperase, situación que venía a demostrar que estas regulaciones especializadas necesitan más de consensos entre las fuerzas políticas y las agrupaciones sociales implicadas y menos de apelaciones al cuerpo electoral, el cual reclama en estos casos más bien información, transparencia y conocimiento de la actuación de sus representantes, que propiamente capacidad de decisión y de dictar la última palabra sobre el asunto.

$\mathrm{Al}$ mismo tiempo, la ley adolece de algunas carencias o establece algunas regulaciones tan rígidas que parece haber optado por privilegiar casi de manera absoluta la posición del embrión, frente a los derechos que pueden asistir a los cónyuges que se someten a este tipo de fecundación artificial. Así, por ejemplo, la ley italiana no consiente en ningún caso la llamada "fecundación heteróloga", esto es, aquélla en que los gametos (masculinos o femeninos) son aportados por al menos un donante diverso a la pareja que se somete a la reproducción asistida. La vinculación de la filiación — también la artificial— únicamente a la procreación biológica (salvo el supuesto, lógicamente, de la adopción), encaja plenamente con la doctrina de la Iglesia Católica, pero encuentra pocos puntos de referencia en el derecho comparado de los países occidentales. En ese ámbito, las diferencias radican principalmente en admitir

\footnotetext{
7 Véase al respecto, por ejemplo, M. Manetti, "Profili di incostituzionalità della legge sulla procreazione assistita", en Politica del Diritto, núm. 3, 2004; C. Casonato, "Legge 40 e principio di non contraddizione: una valutazione d'impatto normativo della disciplina sulla procreazione medicalmente assistita", en Forum di Quaderni Costituzionali; L. Ronchetti, "Donne e corpi tra sessualità e riproduzione", en www.costituzionalismo.it, núm. 2, 2006.
} 
sólo la donación de gametos masculinos (esperma, como es el caso de Alemania), o también de gametos femeninos (ovocitos, como ocurre en buena parte de los países, entre ellos España).

Otra de las insuficiencias que se atribuye a la ley es que la misma sólo contempla la fecundación artificial con el objeto de que parejas estériles o infértiles puedan acceder a la procreación, pero no permite en ningún caso que se haga para evitar la transmisión de enfermedades hereditarias (alteraciones cromosómicas o genéticas), a través por ejemplo de la elección del sexo del embrión.

En el ámbito comparado, prácticamente todos los ordenamientos permiten este tipo de fecundación, con mayor o menor alcance (salvo la legislación austriaca); y en esa línea se enmarca también el "Convenio para la protección de los derechos humanos y la dignidad del ser humano con respecto a las aplicaciones de la Biología y la Medicina" (de 4 de abril de 1997, conocido como "Convenio de Oviedo"), ratificado — entre otros Estados- por España (1999) y por Italia (2001), y que establece en su artículo 14 que "No se admitirá la utilización de técnicas de asistencia médica a la procreación para elegir el sexo de la persona que va a nacer, salvo en los casos en que sea preciso para evitar una enfermedad hereditaria grave vinculada a sexo". Convenio que, no está de más recordarlo, se suele tomar como referente para criticar los posibles excesos de la Ley española 14/2006, de 26 de mayo, "sobre técnicas de reproducción asistida"; y que, al mismo tiempo, es revelador de los posibles defectos de la regulación italiana al respecto.

Esta opción de la ley italiana que impide la selección de embriones para desterrar la posibilidad de transmisión de una enfermedad hereditaria, se justifica en el espíritu de protección del embrión hasta sus últimas consecuencias que informa este texto legislativo, puesto que con ello se evita que los embriones sobrantes sean objeto de destrucción o de crioconservación. En ese mismo sentido se orientan también las previsiones de la ley que limitan el número de embriones que se pueden generar en cada intento de fertilización (hasta tres embriones), lo que lleva aparejado una reducción considerable de las posibilidades de éxito del proceso, con el consiguiente menoscabo y falta de consideración hacia la salud de la mujer, ya que el fracaso en la reproducción conlleva la apertura de nuevos ciclos de estimulación hormonal para lograr aquélla.

En ese mismo espiritu se enmarca la exigencia prevista en la ley de que todos los embriones se implanten en la mujer, en principio incluso con independencia de que el embrión presente graves deficiencias que impidan su desarrollo efectivo; y la imposibilidad de que la pareja revoque su consentimiento para la implantación una vez que se ha producido la fecundación del óvulo. Pero en este supuesto, como se cuestiona la doctrina, ante la negativa de una mujer a la implantación ¿̇cómo se la puede compeler para impedir esta vía indirecta de revocación del consentimiento y preservar, así, lo dispuesto en la ley? Aparte la posibilidad de algún tipo de sanción que no se prevé en la ley, ¿no supone esta obligación derivada de implantación de embriones una vulneración del art. 32 de la Constitución italiana, donde se proscriben los 
tratamientos sanitarios no previstos en las leyes y aquéllos que conlleven la vulneración del debido respeto a la persona? ${ }^{8}$

Resulta revelador de la falta de coherencia de esta regulación legal que un Decreto del Ministerio italiano de Sanidad, en el que se contienen las "Líneas Guía" de aplicación de la ley (pero que no es un reglamento de desarrollo de la misma), haya previsto que, en aquellos supuestos en que un embrión sea inviable, la implantación no será obligatoria y se permitirá el cultivo in vitro del embrión hasta su extinción. Unas previsiones sin duda lógicas, pero que contradicen lo dispuesto en la Ley, norma evidentemente de rango superior.

Por último, las restricciones de la ley se proyectan en relación con los sujetos legitimados para someterse a la reproducción asistida, en esa línea de entendimiento de la familia y de aquéllos que han de poder disponer del derecho a la procreación francamente restrictiva de la que ya hemos hablado. Según lo dispuesto en el art. 5 de la ley, podrán acceder a las técnicas de reproducción asistida médicamente sólo las parejas mayores de edad de diferente sexo, casadas o que convivan, siempre que ambas se encuentren vivas y en edad potencialmente fértil. Una regulación claramente diferente de la que se prevé, por ejemplo, en la legislación española, a partir de lo dispuesto en los arts. 6 a 9 de la Ley 14/2006 (con las modificaciones introducidas con la Ley 3/2007). Quizás comparando las legislaciones española e italiana, y relacionándolas con lo previsto en otros ordenamientos jurídicos, se pondría de manifiesto la necesidad de llegar a este tipo de regulaciones a través de un proceso amplio de debate que dé lugar a un acuerdo de mínimos y no de extremos (por defecto o por exceso) basado en un amplio consenso social y político, como se ha dicho. Un acuerdo tal vez poco satisfactorio para todos, pero no al menos totalmente insatisfactorio para algunos, aunque fuera plenamente satisfactorio para otros.

Sólo así se atemperarían las posibilidades de trasladar el conflicto a los tribunales constitucionales, con el desgaste que ello podría suponer para su posición institucional dentro del sistema, puesto que los mimbres jurídicos de los que se dispone en este tipo de decisiones son a menudo limitados y susceptibles de interpretaciones jurisdiccionales variadas. Esto explicaría por qué la Corte Constitucional italiana no ha entrado a enjuiciar a fondo la ley de reproducción asistida en la ocasión que ha tenido hasta el momento para ello. La Cuestión que da origen a la decisión de la Corte plantea la inconstitucionalidad del art. 13 de la ley 40 de 2004 porque impediría la realización de un diagnóstico preimplante al embrión, antes de la autorización de la implantación, con el objeto de determinar si es portador de una enfermedad hereditaria de la que son portadores los cónyuges. En concreto, el citado precepto limita los supuestos de investigación clínica y experimental en el embrión humano únicamente cuando se persigan finalidades terapéuticas y diagnósticas encaminadas a la salud y al desarrollo del embrión. 
Por lo tanto, la inconstitucionalidad no derivaría propiamente de lo que la ley dispone explícitamente, o de lo que prohíbe directamente, sino de lo que impide indirectamente al no prever expresamente la posibilidad del diagnóstico preimplante, con el consiguiente posible menoscabo de la salud psico-física de la mujer (se vería compelida a un posterior aborto si se verificase que el ya nasciturus es portador de la enfermedad) y la correlativa vulneración de los arts. 2 (derechos inviolables de la persona) y 32 (derecho a la salud) de la Constitución.

Esta complejidad del asunto, unido a que el juicio a quo en el que se plantea la Cuestión tiene como objeto la solicitud de una medida cautelar en la que se declare el derecho de la pareja a obtener un diagnóstico preimplante, permiten a la Corte Constitucional resolver a través de un Auto (Ordinanza núm. 369 de 2006) de inadmisión, en razón de la falta de motivación suficiente, en el auto de planteamiento de la Cuestión, acerca de la relevancia del precepto para la resolución del proceso a quo, y acerca de las causas de su inconstitucionalidad.

Curiosamente, para llegar a esa conclusión de inadmitir la Cuestión la Corte afirma, en su decisión, que la prohibición del referido diagnóstico preimplante no derivaría únicamente del art. 13 de la ley, sino de la ley en su conjunto. Pero obvia al mismo tiempo, aunque razones para este judicial behavior no le faltan, que la ley italiana que disciplina la actuación de la Corte Constitucional le habilita a extender su enjuiciamiento a cualquier precepto de la ley, aunque no haya sido cuestionado. No obstante, si hubiera optado por seguir ese camino, queda por preguntarse qué tipo de pronunciamiento podría haber realizado la Corte sin sustituir al legislador positivo. ¿Podría afirmar la inconstitucionalidad de la ley por no prever ese tipo de diagnóstico? ¿Podría delimitar el alcance que debería tener la regulación legal sobre esa materia?

\section{TUTELA DE DERECHOS: AUTORIDADES INDEPENDIENTES Y TEDH}

Resta por llevar a cabo un breve apunte final sobre algunas cuestiones relativas a la tutela de los derechos de la persona, de menor alcance ético y trascendente, para aliviar así la carga emocional de lo escrito hasta ahora. En primer término, es interesante traer a colación la trascendencia que se viene dando en el ordenamiento italiano a las autoridades independientes, como garantes y reguladoras de determinados sectores vinculados con los derechos fundamentales.

Así ha ocurrido, en concreto, respecto de la privacy y de la libertad de información, y de las atribuciones que corresponden al "Garante de la Privacy" para proteger los datos personales de los ciudadanos frente a las intromisiones derivadas del ejercicio de las libertades informativas, según lo dispuesto en el "Código en materia de protección de datos personales" (Decreto Legis- 
lativo núm. 196 de 2003). La controversia ha surgido por dos decisiones de dicho Garante que la mayor parte de la doctrina ha considerado excesivas: Una, la prohibición hecha a los medios de comunicación de difundir datos personales de los diputados (en relación con su posible consumo de estupefacientes) con base en su competencia para prohibir el tratamiento ilícito de datos. Otra, la prohibición pro futuro y para todos los medios de comunicación de tratar y dar noticia de los datos sexuales de un determinado político, una vez que ciertas informaciones al respecto hubieran aparecido en un medio.

En cuanto al primer supuesto, este control ex-ante vendría a suponer una vulneración del art. 21 de la Constitución italiana, que proscribe que se pueda someter a la prensa a autorización previa o a censura; y ello sería así por más que la decisión que produce esos efectos provenga de una autoridad independiente. En el segundo supuesto, el exceso de la actuación del Garante se pondría de manifiesto en que, con esa prohibición, se estaría creando una suerte de inmunidad total respecto de una persona con evidente relevancia pública, a través de una prohibición de categorías abstractas de comportamientos que se proyecta, además, sobre todos los periodistas y sobre todo tipo de conductas de los mismos. Más que una censura, se trataría de un poder de bloqueo del Garante sobre las actuaciones de los medios de comunicación.

Dicho de otra forma, si la preservación de la privacy es una cuestión que trasciende el ámbito privado de su titular y ha pasado a ser, en las sociedades democráticas de nuestros días, una función pública que tiene como objeto sustraer al individuo al control abusivo del poder (S. Rodotà), parece claro que la creación de autoridades independientes encargadas de garantizar los derechos de la privacidad no constituye un mecanismo suficiente para preservar los derechos constitucionales en juego, toda vez que, en el ejercicio de sus potestades (de su poder público), la autoridad independiente puede menoscabar también libertades esenciales.

Como cierre de esta Crónica, sólo dos apreciaciones respecto de la fuerza vinculante y la ejecución de las sentencias del Tribunal Europeo de Derecho Humanos en territorio italiano. En una decisión reciente, el Tribunal Supremo de este país (asunto Somogyi, Sentencia de 12 de julio de 2006, núm. 32678) ha afirmado la vinculación plena de los jueces italianos a las sentencias de condena pronunciadas por el TEDH que versen sobre los mismos hechos objeto de la causa. En una tendencia seguida por otros ordenamientos europeos (no por el español) para dotar de efectividad a las decisiones del Tribunal de Estrasburgo en el ámbito interno, la sentencia referida llama la atención porque ese objetivo no se alcanza a través de previsiones legislativas (Austria), o a través de la jurisprudencia constitucional (Alemania), sino por medio de una decisión de la Casación.

Sentencia que, sin embargo, adolece de una insuficiente motivación, puesto que se basa en lo previsto en el art. 46 del Convenio acerca de la fuerza obligatoria y la ejecución de las sentencias del TEDH, y en las modificaciones que incorpora el Protocolo núm. 14 a este artículo, para deducir de ahí que esa fuerza vinculante no sólo compromete al Estado, sino también a sus 
órganos, incluidos los jueces y tribunales. Pero, dejando a un lado el hecho de que el Protocolo núm. 14 aún no ha entrado en vigor a día de hoy, aunque haya sido ratificado, entre otros, por el Estado italiano (también por el español), es preciso señalar que tampoco la nueva regulación del art. 46 contenida en ese Protocolo permite deducir ese tipo de efectividad de las sentencias del TEDH, puesto que éste se limita a prever un recurso a favor del Consejo de Ministros para que el Tribunal Europeo de Derechos Humanos determine la existencia del incumplimiento de una sentencia por un Estado, y a habilitar al Consejo de Ministros a adoptar medidas si dicho incumplimiento es constatado por el TEDH.

Claro que, en ocasiones, las previsiones del legislador son claramente insuficientes para reducir el alcance de la soberanía estatal en la ejecución de las sentencias del Tribunal de Estrasburgo. Como ocurre, de hecho, en la Ley italiana núm. 12 de 2006, en la que se atribuye al Presidente del Consejo de Ministros «... promover el cumplimiento de los pronunciamientos del Tribunal Europeo de Derechos Humanos contra el Estado italiano en asuntos de competencia del gobierno; comunicar inmediatamente a las Cámaras dichos pronunciamientos con el objeto de su examen por parte de las comisiones parlamentarias permanentes competentes; y presentar anualmente al Parlamento una relación sobre el estado de ejecución de dichos pronunciamientos".

ABSTRACT. Nowadays, the development of fundamental rights finds new spaces of expansion related to, among other subjects, the recognition of citizenship and the rights of foreigners, the satisfaction of new social demands that do not have express recognition in constitutional texts (such as the rights of unmarried couples - hetero or homosexual-), or the appropriate regulation of the new challenges that derive from the advances of science and the appropriate consideration of the varied rights and interests involved (for example, as it happens with test-tube fertilization and treatment of human embryos). Italian Law proves still to be resistant to adapt to those new challenges, without needing be to give up the ethical component that must preside over its legal discipline. In any case, that component must be looked up in the constitutional text and its update interpretation, but not in a morality that tries to establish itself as the collective morality of a society, even though it doesn't become morality of State. 